\title{
Effective removal of total organic carbon from soil polluted with agricultural solid waste leachate using electrocoagulation
}

\author{
Xu Han ${ }^{1,2}$, Guangchun Liu ${ }^{1, *}$, Kun $\mathrm{Liu}^{2}$, Ting $\mathrm{Li}^{2}$ \\ ${ }^{1}$ Liaoning Provincial Key Laboratory of Urban Pest Management and Ecological Safety, ShenYang \\ University, ShenYang 110044, China \\ ${ }^{2}$ Green Island Institute of Environmental Resources, ShenYang City University, Shenyang 110112 , \\ China \\ *E-mail: liuguangchun666@ sina.com
}

doi: $10.20964 / 2021.06 .07$

Received: 2 February 2021 / Accepted: 22 March 2021 / Published: 30 April 2021

\begin{abstract}
This study focused on treatment of total organic carbon (TOC) and chemical oxygen demand (COD) from soil pollution of agricultural solid waste leachate using electrocoagulation by $\mathrm{Al}$ and $\mathrm{Fe}$ nanocomposite (Al@Fe) electrodes. Al@Fe was synthesized through an electrodeposition method. Study of morphology and crystalline structure of the sample by SEM and XRD analyses showed that the electrodeposited samples consisted of spherical nanoparticles of $\mathrm{Al}$ in fcc crystal structure and $\mathrm{Fe}$ in polycrystalline $\alpha$-iron metallic which homogeneously distributed in the composite matrix. Moreover, the effects of initial $\mathrm{pH}$, current density and $\mathrm{Fe}$ concentration in nanocomposite content on electrocoagulation treatment were examined. Results showed COD and TOC removal efficiencies were obtained $95 \%$ and $96 \%$, respectively after 60 minutes electrocoagulation treatment in $2 \mathrm{gl}^{-1} \mathrm{NaCl}$ as a supporting electrolyte under optimal condition $(\mathrm{pH} 6)$ and applied current density of $1 \mathrm{~mA} / \mathrm{cm}^{2}$ at room temperature using Al@Fe electrode with equal concentration of $\mathrm{Al}$ and Fe. Results indicated that synergetic effect of $\mathrm{Al}$ and $\mathrm{Fe}$ nanoparticles in nanocomposites electrodes provided the higher effective surface and fast electron transfer rate for electrochemical treatment.
\end{abstract}

Keywords: Electrocoagulation; Total organic carbon; Chemical oxygen demand; Agricultural solid waste leachate; Nanocomposite

\section{$\underline{\text { FULL TEXT }}$}

(C) 2021 The Authors. Published by ESG (www.electrochemsci.org). This article is an open access article distributed under the terms and conditions of the Creative Commons Attribution license (http://creativecommons.org/licenses/by/4.0/). 